\title{
Erratum to: Role of Glutathione Peroxidases and Peroxiredoxins in Free Radical-Induced Pathologies
}

\author{
Mars G. Sharapov ${ }^{1, a *}$, Sergey V. Gudkov²,3,4, Vadim Z. Lankin ${ }^{5}$, and Vladimir I. Novoselov ${ }^{1}$ \\ ${ }^{1}$ Institute of Cell Biophysics, Russian Academy of Sciences, 142290 Pushchino, Moscow Region, Russia \\ ${ }^{2}$ Prokhorov Institute of General Physics, Russian Academy of Sciences, 119991 Moscow, Russia \\ ${ }^{3}$ Institute of Biology and Biomedicine, Lobachevsky State University of Nizhni Novgorod, 603022 Nizhny Novgorod, Russia \\ ${ }^{4}$ All-Russian Research Institute of Phytopathology, 143050 Bolshiye Vyazemy, Russia \\ ${ }^{5}$ National Medical Research Center of Cardiology, Ministry of Health of Russia, 121552 Moscow, Russia \\ ae-mail: sharapov.mars@gmail.com
}

Received May 27, 2021

Revised September 19, 2021

Accepted September 19, 2021

DOI: $10.1134 / \mathrm{S} 0006297921120129$

The original article can be found online at https://doi.org/10.1134/S0006297921110067

The original article has been corrected. The name of the first author was spelled incorrectly. The erroneous variant Mars G. Shaparov was corrected to Mars G. Sharapov. 